\title{
RESEARCH ON WORK METHODS FOR TUGS IN PORTS
}

\author{
Vytautas Paulauskas ${ }^{1}$, Donatas Paulauskas ${ }^{2}$ \\ Klaipeda University, H. Manto g. 84, LT-92294 Klaipeda, Lithuania \\ E-mails: 1donatasp@takas.lt (corresponding author); ${ }^{2}$ pdonatas@takas.lt
}

Received 5 January 2010; accepted 25 July 2011

\begin{abstract}
Tug assistance in ports for increasing ship maneuverability, mooring and unmooring operations is a very important issue. New tugs are given increased possibilities; nevertheless, at the same time, work methods for tugs, including advantages and disadvantages must be carefully studied, evaluated and practically applied.

The article presents the results of the carried out research on the work methods of a new type of tugs, thus offering recommendations for how to avoid drawbacks of working with new tugs during ship mooring operations.
\end{abstract}

Keywords: tug towing power, work methods for tugs, ship mooring operations.

\section{Introduction}

An increase in ship parameters requires more assistance of tugs to enhance maneuverability as well as mooring and unmooring operations in ports (Baublys 2003). New ship sizes such as PANAMAX, POST PANAMAX, POST PANAMAX Plus and finally Mega ships have been built during the last decades. However, at the same time, port channels and water places have not progressed as fast as the parameters of ships (Paulauskas 2004), which requests more tug assistance, the use of new towing methods and new types of tugs having wider possibilities of maneuvering, for example, an azimuth rudder-propeller system ('Azipod system') and new more accurate navigational systems in ports, including real time kinematics (RTK), lasers etc. (Paulauskas, V., Paulauskas, D., 2009; E-Sea Fix navigation system 2003).

Simultaneously, a number of new powerful tugs and work methods for tugs face advantages and disadvantages that must be carefully studied to make them more effective in using tugs and increasing their possibilities. Theoretical investigations into the new types of work methods for tugs in ports, experimental tests on real ships and calibrated simulators were the main research direction to prepare a methodology of calculating tug towing power under real conditions, which is an important issue and the need for future investigations and practical calculations of tug bollard pull.

The article focuses on the situation of work methods for tugs in ports, discusses a theoretical basis for calculating tug bollard pull, examines experimental and testing results and provides conclusions.

\section{Using Tugs in Ports}

Ports use conventional and new tugs equipped with 'Azipod systems' for increasing the maneuverability of ships entering the port and for ships conducting mooring and unmooring operations. Old conventional tugs mainly apply short tug lines for increasing ship maneuverability, and therefore are used for pushing ships. This towing system is not flexible enough as it requests more water areas near quay walls, more wide channels etc.

New tugs equipped with 'Azipod systems' ('tractor' type) have a greater number of maneuvering possibilities and can move in any direction with more or less the same pull or pushing power (Fig. 1).

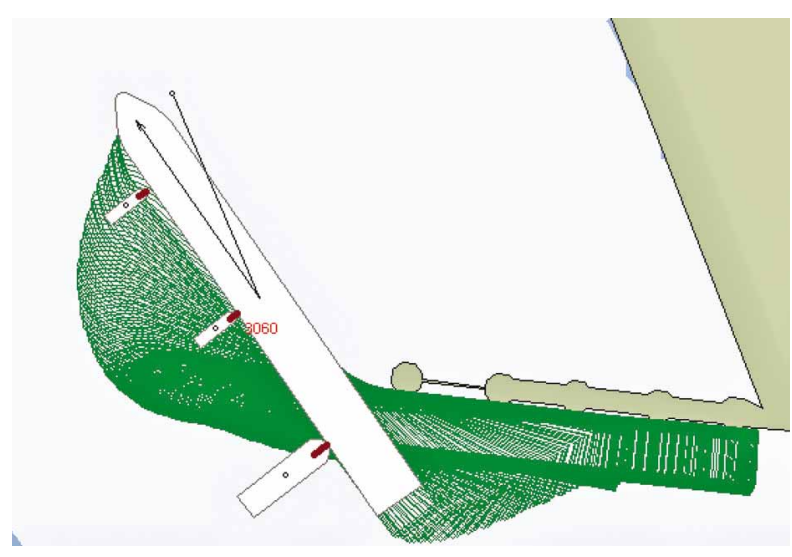

Fig. 1. A new type of tugs used for ship mooring operations applying the push/pull method 
Nowadays, tugs equipped with the 'Azipod system' and propulsion systems of vertical wings frequently use the push/pull method to provide assistance in ship maneuvering that requires less water area. This means that to turn or move to/from the quay wall within limited port areas is a big advantage to the maneuverability of big ships.

To provide assistance in ship maneuverability, for tugging, conventional tugs mainly employ the system of short ropes, which needs more space (water area) and in many cases, a longer period of time for changing the moving direction of the ship (Paulauskas 1998). Fig. 2 displays the method of short lines of tug towing that can be used by any type of tugs.

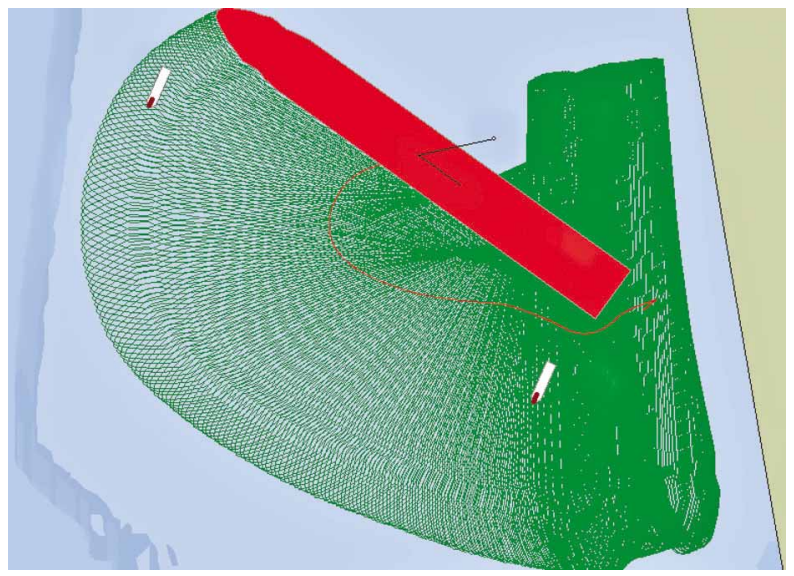

Fig. 2. The method of tug towing using short ropes can be used of any type of tugs

At the same time, towing methods include both advantages and disadvantages, particularly in the case of towing big draft ships and used tugs having limited possibilities of push/pull force.

Theoretical and practical investigations into advantages and disadvantages of the new type of work methods for tugs in ports, especially the method of assistance in tug pushing/pulling, are very important for the correct and optimal use of the new types of tugs providing assistance in ship maneuvering and mooring.

\section{The Theoretical Basis for the Method of Tug Pushing/Pulling}

The method of tug pulling/pushing could be used for a number of ship maneuvering operations in port areas (Fig. 3), because the technique requires less water area, and therefore maneuvers could be initiated during a shorter period of time and take better control from the ship bridge over the tug working process (BS 63491:2000; BS 6349-4:2000; Criteria for Movements... 1995; Guidelines for the... 2002; Recommendations of the Committee... 2006).

The force for tug pulling/pushing could be calculated as follows:

$$
F_{T}=K_{1}^{\prime} \cdot \rho \cdot n^{2} \cdot D_{p}^{4}\left(1-t^{\prime}\right)-R_{T},
$$

where: $K_{1}^{\prime}$ - the propeller coefficient for practical calculators can be accepted as $0.20 \div 0.22$; $\rho$ - water densi- ty, $\mathrm{kg} / \mathrm{m}^{3} ; n$ - propeller revolutions, $\mathrm{s}^{-1} ; D_{p}$ - the diameter of the propeller, $\mathrm{m} ; t^{\prime}-$ the coefficient of propeller propulsion for practical calculations can be agreed as $0.15 \div 0.20 ; R_{T}$ - tug resistance when speed is very low (ship mooring or unmooring conditions), $R_{T}$ is close to 0 .

When applying the push/pull method, a tug and a ship are linked close to each other. In the case when the tug is pushing the ship, the force of pushing is equal to the calculated formula (1). In case of ship pulling, two very important elements must be taken in account (Çakmak, Ersöz 2007; Paulauskas et al. 2008, 2009; Paulauskas 2010):

- the vertical angle of the tug line;

- the effect of the water flow produced by the screw propeller on the ship board.

The vertical angle of the tug line decreases horizontal tug power as shown in Fig. 4 and can be calculated as follows:

$$
F_{w}=F_{T} \sin \alpha,
$$

where: $\alpha$ - the vertical angle of the tug line.

It is also necessary to consider an increase in the length of the tug line.

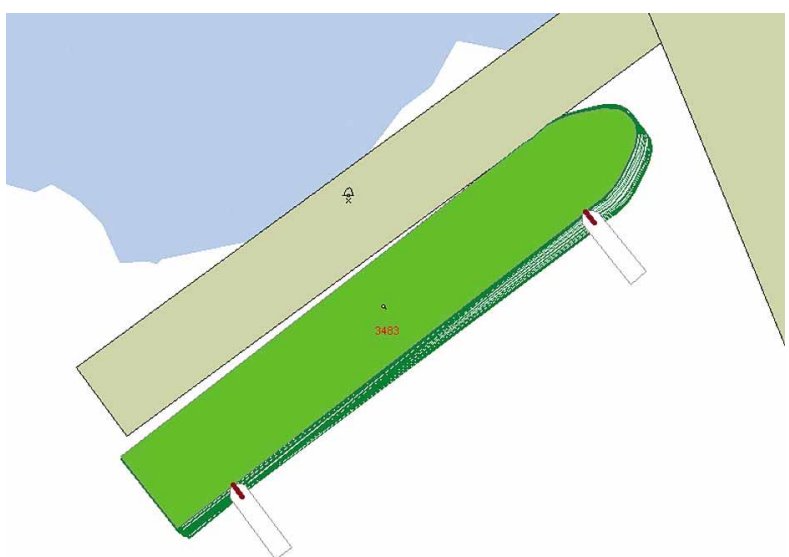

Fig. 3. The method of tug pushing/pulling used for ship mooring operations

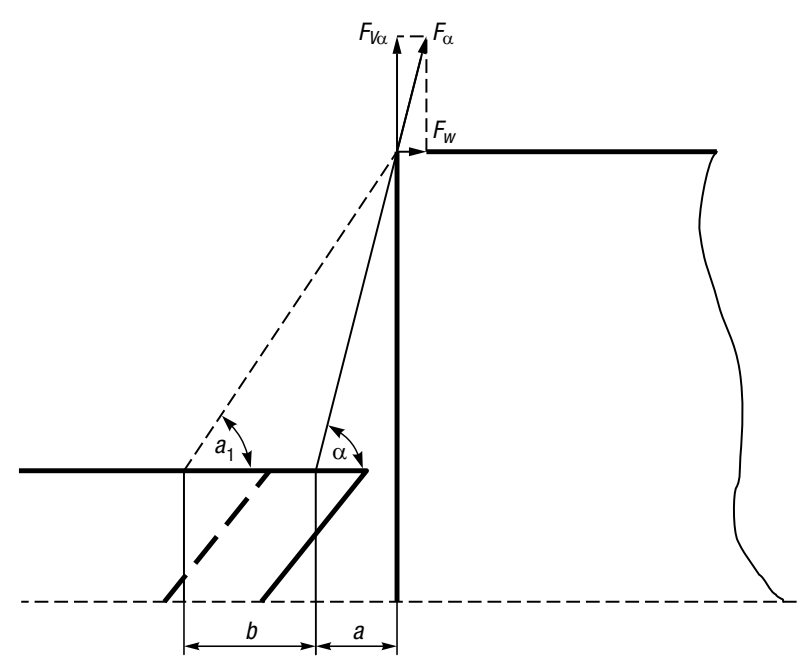

Fig. 4. Vertical angle $\alpha$ and changes of the tug rope. 
An increase in the length of the tug line when using synthetic ropes could reach up to $20 \%$; in such case, changes in the vertical angle could be calculated as follows:

$$
\alpha_{1}=\arcsin \frac{h}{1.2 \cdot l}
$$

where: $h$ - height between tug winch and ship tug line fixed on the cross point of the board; $l$ - the original length of the tug line.

In some ports, during pulling operation when using the method of tug pulling/pushing the distance between the ship and tug increases up to $10 \div 15 \mathrm{~m}$ (using tug winch). In such case, angle $\alpha_{1}$ can be calculated as follows:

$$
\alpha_{2}=\operatorname{arctg} \frac{h}{a+b} .
$$

Changes in the distance between the tug and effect of ship board are used frequently on tugs to increase the force of tug pulling.

The flow produced by the screw propeller and caused by the effect of the stern screw of the propeller usually is not taken into account in many cases; however, this effect could have a considerable influence on the force of tug pulling. Jet velocity caused by the rotating screw, the so called induced jet speed, can be calculated in the following way (Recommendations of the Committee... 2006):

$$
v_{0}=1.6 \cdot n \cdot D_{p} \cdot \sqrt{k_{T}},
$$

where: $k_{T}$ - the thrust coefficient of the screw that could be taken for study case $0.30 \div 0.40$.

The distance of the induced jet speed for tugs can be calculated as follows:

$$
v_{0}^{\prime}=k_{v} \cdot v_{0} \text {, }
$$

where: $k_{v}$ - the coefficient of the induced jet speed depends on the diameter of the tug propeller and the distance between the propeller and checking point (ship hull) and was received conducting theoretical investigations and experimental tests on real tugs presented in Fig. 5.

The induced jet speed produced by screw propellers used in tugs directly influences ship hull (create resistance depending on the hull shape of the pulled ship) square affected by the induced jet (Fig. 6), which is equal to the square of the crew propeller and can be calculated as follows:

$$
A=\pi\left(\frac{D_{P}}{2}\right)^{2} .
$$

Additional force created by the screw propeller can be calculated as follows:

$$
F^{\prime}=C_{y} \cdot \frac{\rho}{2} \cdot A \cdot\left(v_{0}^{\prime}\right)^{2} \cdot n_{p},
$$

where: $C_{y}$ - the hydrodynamic coefficient taken from 0.5 to 2.0 (2.0 is used in case if the screw propeller acts in a perpendicular manner to the ship hull as to the vertical wall, which conforms to the pulled ship having highdraft); $n_{p}$ - the number of tug propellers.

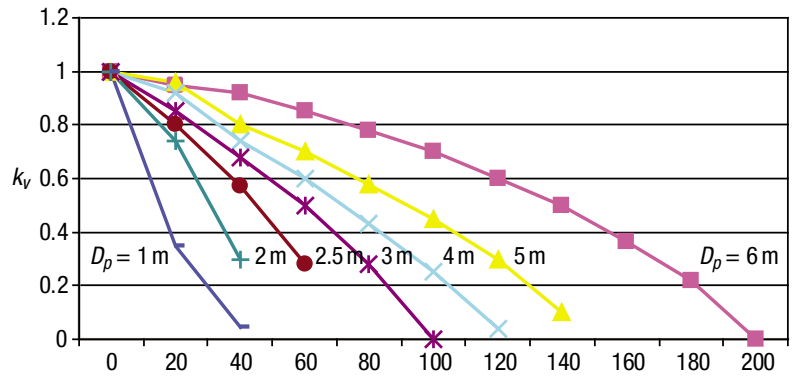

Fig. 5. The coefficient of the induced jet speed depends on the diameter of the tug propeller and the distance between the propeller and checking point (ship hull)

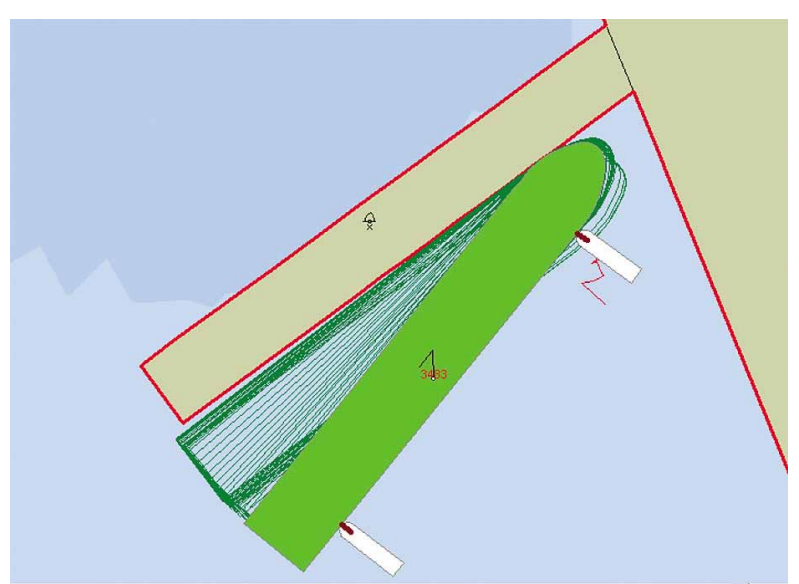

Fig. 6. Ship pulling by tugs applying the push/pull method

Finally, the total force of tug pulling employing the pull/push method when the tug is located close to the ship can be calculated as follows:

$$
\sum F_{T}=F_{T} \cdot \cos \alpha-C_{y} \cdot \frac{\rho}{2} \cdot A \cdot\left(v_{0}^{\prime}\right)^{2} \cdot n_{p} .
$$

The last formula shows that if the vertical angle of the tug rope is very big (close to $90^{\circ}$ ), pulling force could be very low or in some cases could make a negative effect, which means that the pressure force created by the screw propeller on the hull shape of the pulled ship can be greater than that used for towing a tug boat).

\section{Test Results and Analysis}

For practical study, real ships that make mooring and unmooring operations in Klaipeda port applying 'Tractor' tugs on the basis of real experimental results and using SimFlex Navigator Simulator (SimFlex Navigator Simulator 2009) were calibrated. The quay walls located perpendicularly to the current direction were used for conducting a test applying SimFlex Navigator Simulator and a container vessel the overall length of which was $-215 \mathrm{~m}$, width $-32.2 \mathrm{~m}$, draft $-9.5 \mathrm{~m}$ and displacement $-39740 \mathrm{~m}^{3}$. For mooring operations, 2 'Tractor' tugs, having $300 \mathrm{kN}$ pull force each were employed. During unmooring operations, tugs used the push/pull method and short ropes. The current speed towards the quay wall was 0.5 knots when tugs referred to the push/ pull method (Fig. 1) and 0.8 knots when tugs used short ropes for tug towing (Fig. 2). 
Figs 7-9 present testing results when tugs use the push/pull method depending on time (vertical line in Fig. 8 shows actual ship position in Fig. 7). Vertical angles of the tug ropes made 65 degrees in the fore and 60 degrees in the aft of the ship.

Under similar environmental conditions (current flows with a speed of 0.8 knots to the quay wall), the same tugs and short ropes were applied for pulling the container vessel from the quay wall. The obtained results are presented in Figs 10 and 11.

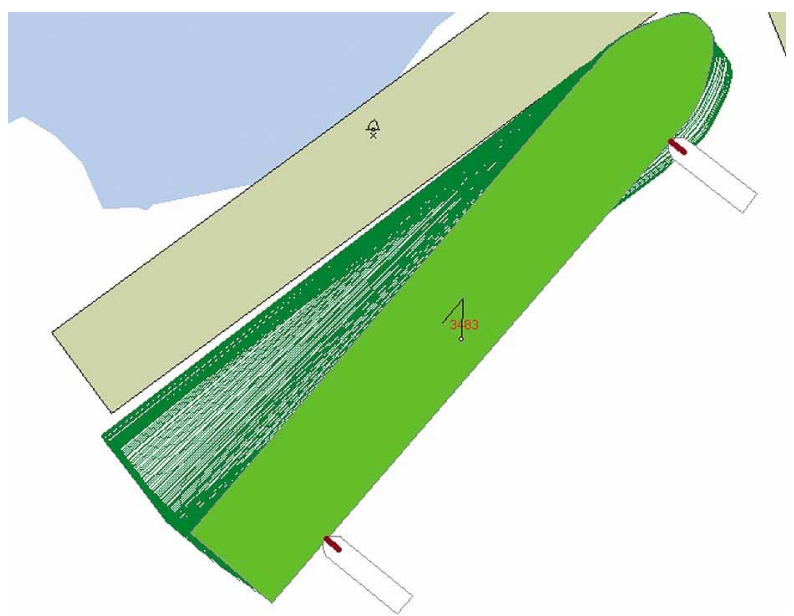

Fig. 7. A container vessel unmoored by two tugs using the pull/push method

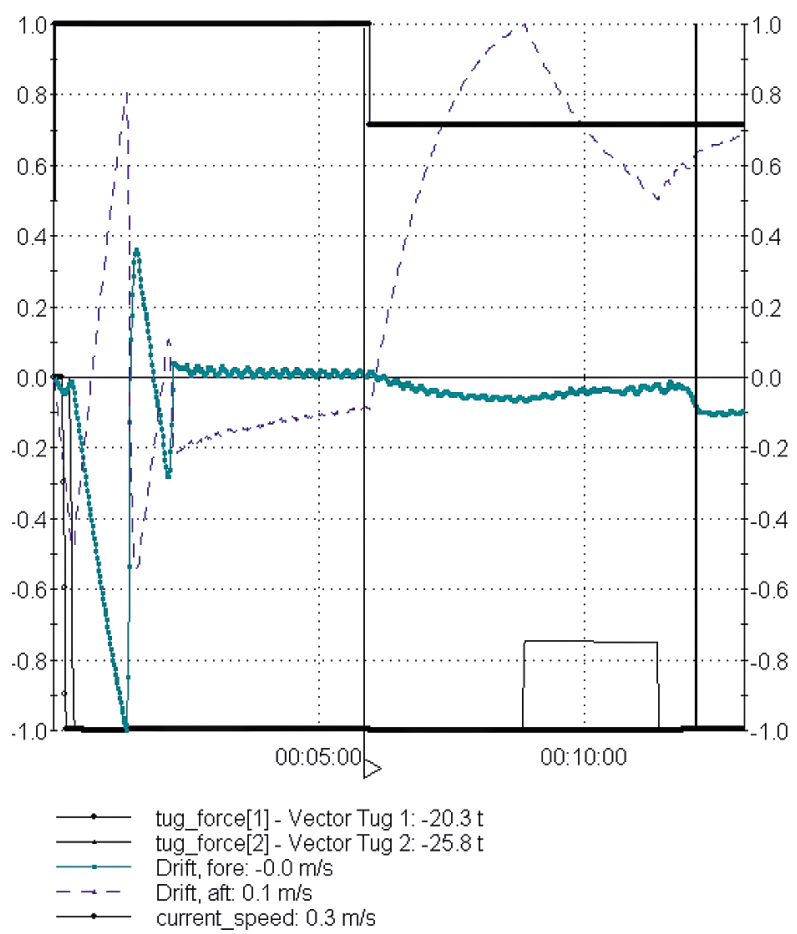

Fig. 8. The movement of a container vessel from the quay wall (drift), tug pulling force and data on the current speed. Up to 6.00 minutes, the current speed was 0.8 knots, later decreased up to 0.6 knots. The vertical line in Fig. 8 (time: 12 minutes) shows the position of the container vessel presented in Fig. 7

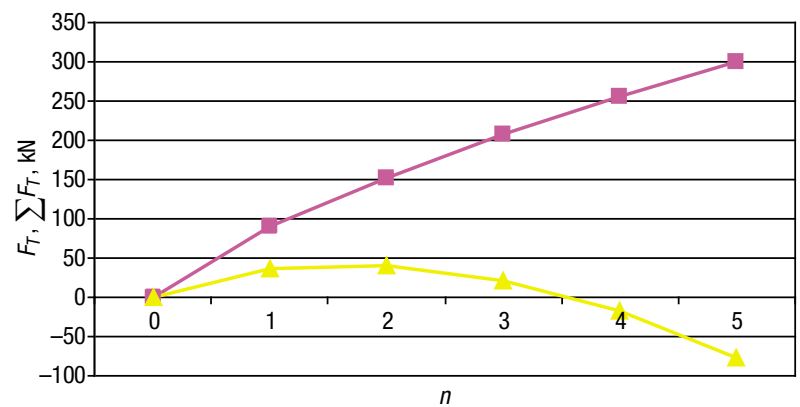

Fig. 9. The tug pulling force $\left(F_{T}\right)$ of $300 \mathrm{kN}$ (red line) depending on propeller revolutions and the total tug pulling force $\sum F_{T}$ (yellow line) using the pull/push method when the vertical angle of the tug line $-60^{\circ}$, the diameter of the tug propeller $-2.0 \mathrm{~m}$, the number of propellers -2 , the distance between tug propellers and ship hull $-25 \mathrm{~m}$

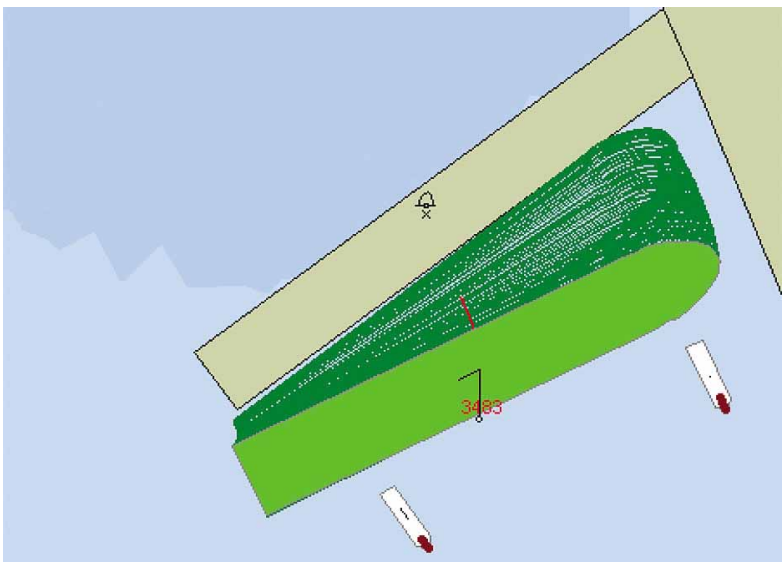

Fig. 10. A container vessel unmooring operation employing two tugs and using the method of applying short ropes for tug towing

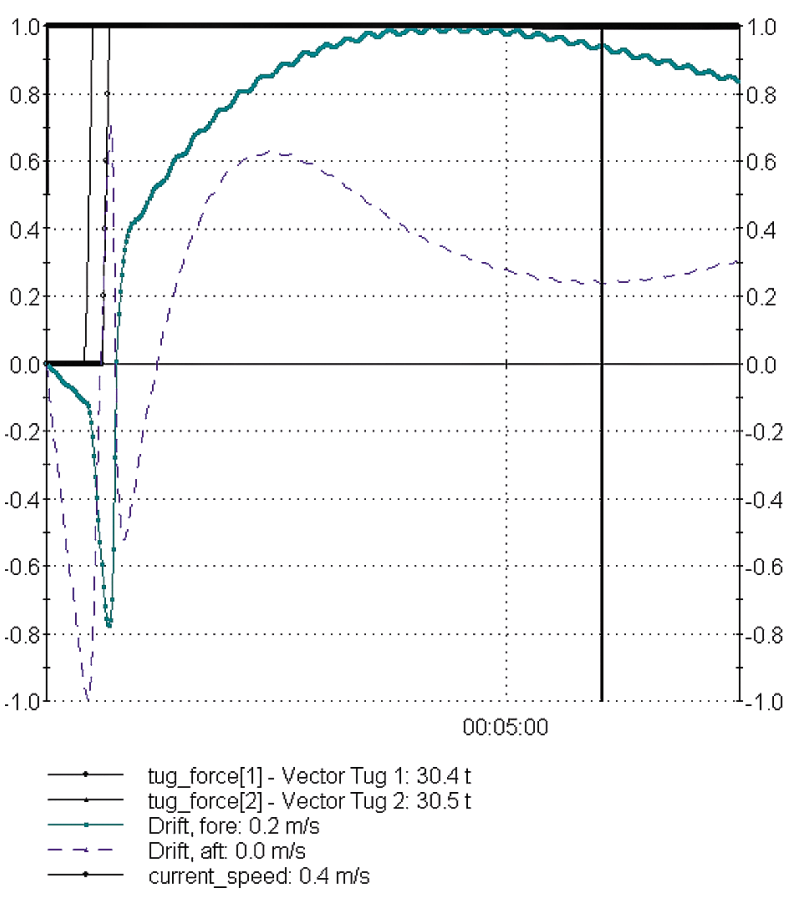

Fig. 11. The movement of a container vessel from the quay wall (drift), tug pulling force and data on the current speed. The current speed was 0.8 knots. The vertical line in Fig. 11 shows the position of a container vessel presented in Fig. 10 
The carried out tests fixed time, the speed and acceleration of a container vessel and provided a comparison with calculation results. As shown in Figs 8 and 11 , in case of using the method of applying short ropes for tug towing, within 3 minutes, the container vessel reached a higher drift speed rather than when employing the pull/push method within the period longer than 10 minutes under the same environmental conditions.

\section{Conclusions}

1. New tugs can work more flexibly with ships to increase their maneuverability in mooring and unmooring operations; however, simultaneously, disadvantages caused by work methods should be deeply studied taking into account the obtained results.

2. In case of pushing a ship to the quay wall or considering other conditions, the method of tug pushing/pulling can be very effective and the force of tug pushing is equal to the maximum force of tug pulling calculated using formula (1).

3. The coefficient of the induced jet speed depends on the diameter of the tug propeller and the distance between the propeller and ship hull when a big draft of the towing ship received in this study could be accepted as the basis for calculating the forces of tug pulling.

4. When a ship is pulled from the quay wall against the current and wind in case of limited tug pulling possibilities, depending on the vertical angle of the tug line and the distance between the tug propeller and ship, the pulling force of the tug could be very weak and in some cases have a negative influence on the ship, as explained in Fig. 9. The pulling forces of the tug depend on the draft of the pulled ship and hull shape in the place where the tug to the pulled ship appears. In case of the low effectiveness of the tug, to pull a ship, it is necessary to use other methods of work, for example, short ropes could be more useful and effective.

5. Depending on the pulled ship and tug working methods, the received dependences and methodology for an accurate calculation of tug pulling forces are new in the ship handling theory and practical experience.

6. The methodology presented in the article could be used for investigating work methods of tugs and for preparing special recommendations that depend on the geometrical parameters of ships (draft, the fixed points of tugs etc.), and therefore help with avoiding disadvantages experienced when applying new working methods for tugs.

\section{References}

Baublys, A. 2003. Transport system: models of development and forecast: monograph. Vilnius: Technika. 208 p.

BS 6349-1:2000. British Standard. Maritime Structures. Code of Practice for General Criteria.

BS 6349-4:2000. British Standard. Maritime Structures. Code of Practice for Design of Fendering and Mooring Systems.

Çakmak, T.; Ersöz, F. 2007. Methodology recommendation for one-criterion transportation problems: CAKMAK method, Transport 22(3): 221-224.
Criteria for Movements of Moored Vessels in Harbours. 1995. PIANC.

E-Sea Fix Navigation System. 2003. Marimatech, Denmark. 120 p. Guidelines for the Design of Fender Systems. 2002. PIANC.

Paulauskas, V. 1998. Laivo valdymas ypatingomis salygomis [Ship's steering in complicate conditions]. Klaipeda: Klaipèdos universiteto leidykla. 164 p. (in Lithuanian).

Paulauskas, V. 2004. Uostu terminaly planavimas [Ports terminal planning]. Klaipeda: Klaipèdos universiteto leidykla. 382 p. (in Lithuanian).

Paulauskas, V. 2010. Ship passing through straits, Transport 25(4): 345-351. doi:10.3846/transport.2010.42

Paulauskas, V.; Paulauskas, D. 2009. Laivo valdymas uoste [Ship's steering in seaport], Klaipedda: Klaipedos universiteto leidykla. 256 p. (in Lithuanian).

Paulauskas, V.; Paulauskas, D.; Wijffels, J. 2008. Ships mooring in Complicated Conditions and possible solutions, in Proceedings of the 12th International Conference 'Transport means', 67-70.

Paulauskas, V.; Paulauskas, D.; Wijffels, J. 2009. Ship safety in open ports, Transport 24(2): 113-120. doi:10.3846/1648-4142.2009.24.113-120

Recommendations of the Committee for Waterfront Structures Harbours and Waterways (EAU 2004). 2006. 8th edition. Wiley. $660 \mathrm{p}$.

SimFlex Navigator Simulator. 2009. Force Technology, Denmark. 